\title{
Institutioning the common. The case of Commonfare
}

\author{
Maurizio Teli \\ Madeira Interactive \\ Technologies Institute \\ Funchal, Portugal \\ maurizio.teli@m-iti.org
}

\author{
Peter Lyle \\ Madeira Interactive \\ Technologies Institute \\ Funchal, Portugal \\ peter.lyle@m-iti.org
}

\author{
Mariacristina Sciannamblo \\ Madeira Interactive \\ Technologies Institute \\ Funchal, Portugal \\ cristina.sciannamblo@m-iti.org
}

\begin{abstract}
Participatory Design (PD) has recently seen efforts to reinvigorate its political capacity, including reflections on the relations between its practices and institutions and a renewed political agenda in the contemporary stage of capitalism, such as the one of nourishing the common. This paper addresses both of these directions, questioning how a renewed political agenda of PD intersects the processes of institutioning in which PD itself takes part. To do that, we refer to an European-funded project called Commonfare, aimed at designing a digital platform fostering the emergence of a new economic model in the domain of the institutions of the welfare state. We conclude by discussing how a PD political agenda based on the critique of the current forms of capitalism aligns with or challenges existing institutional frames, supporting the emergence of new institutions.
\end{abstract}

\section{CCS CONCEPTS}

- Human-centered computing $\rightarrow$ Collaborative and social computing theory, concepts and paradigms; Empirical studies in collaborative and social computing;

\section{KEYWORDS}

Participatory Design, Institutioning, Digital Platforms, Commoning

\section{ACM Reference Format:}

Maurizio Teli, Peter Lyle, and Mariacristina Sciannamblo. 2018. Institutioning the common. The case of Commonfare. In PDC '18: Proceedings of the 15th Participatory Design Conference - Volume 1, August 20-24, 2018, Hasselt and Genk, Belgium. ACM, New York, NY, USA, 11 pages. https: //doi.org/10.1145/3210586.3210590

\section{INTRODUCTION}

Digital technologies of today are pervasive within social life, in a way that transcends an instrumental or even hedonistic view of technologies, revealing how contemporary digital corporations are more and more disciplining social relations and economic life. This is taking place both through the effort of disrupting existing economic domains - like in the case of Amazon, or "sharing economy" companies as Uber or AirBnb - or through the commodification of social relations that does not necessarily involve financial transactions among the general public, like in popular social media such

Permission to make digital or hard copies of part or all of this work for personal or classroom use is granted without fee provided that copies are not made or distributed for profit or commercial advantage and that copies bear this notice and the full citation on the first page. Copyrights for third-party components of this work must be honored.

For all other uses, contact the owner/author(s).

PDC '18, August 20-24, 2018, Hasselt and Genk, Belgium

(C) 2018 Copyright held by the owner/author(s).

ACM ISBN 978-1-4503-6371-6/18/08.

https://doi.org/10.1145/3210586.3210590 as Facebook and in the services provided by Google. The combination of data collection and manipulation through increasingly advanced machine learning technologies is driving the competitive advantage of these firms and their effort to become monopolies in the respective sectors, as well as their competitive convergence in what Nick Srnicek defines as "platform capitalism" [1].

The unfolding of platform capitalism is not taking place without frictions, conflicts, or alternative agendas. For example, the platform cooperativism movement is questioning the ownership of digital platforms [2], arguing in favor of workers-owned cooperatives as the most appropriate institutional forms for contemporary platforms while long-term initiatives inspired by peer-to-peer collaboration and commons-based peer production have acquired more visibility and capacity to influence governments and local administrations [3]. At the same time, trade unions, like the German IG Metall, have started to consider the transformation of labor and the need for new forms of unionization [4], or new forms of collective actions have emerged to accommodate the need of free-lancers including, for example, riders of Deliveroo [5]. The alternatives to contemporary forms of capitalism refers to approaches oriented to nourish what is common among people, often in the institutional form of commons, as democratic governance arrangements to manage shared resources [6], reflecting contemporary intellectual and practical efforts among critical scholars and social movements $[7,8]$.

In the intellectual milieu engaging with what is common among people, Participatory Design's (henceforth, PD) initial focus on the relationship between technologies and labor makes researchers in PD potentially relevant social actors in the struggle between capital and labor that characterizes contemporary societies in the Global North for different reasons. First of all, PD is strongly equipped to conceptualize technologies as part of people lives, not only considering the interaction between humans and machines, but also framing technologies as a site of political struggle that people have a right to shape [9]. Second, PD has been discussing how design could become part of democratic experiments based on the ethnographic and collaborative understanding of the social domain in which technologies can unfold, and that has provided researchers and practitioners with insights on how such democratic experiments could be understood [10]. Finally, PD scholars have started updating the political agenda of PD through a series of useful projects, perspectives, and concepts - including infrastructuring, publics, institutioning, feminist theory, and nourishing the common - which have the potential to reassess the political capacity of PD beyond its initial focus on the workplace.

In this paper, we refer to two main perspectives among the ones mentioned, PD nourishing the common [11-13] and institutioning [14]. By nourishing the common we refer to PD practices able to strengthen the connections among human beings, through material 
or symbolic resources, and we call 'the common' the ensemble of such resources tying together human beings [15]. Through institutioning, we conceptualize PD practices as immersed in institutional contexts and engaging with such contexts stimulating change in existing institutions or promoting the emergence of new ones $[14,16]$. With the expression "institutioning the common" we refer to the combination of these perspectives, looking at how the institutioning work in PD practices can actually intersect with practices and processes nourishing the common.

Empirically, this paper frames, presents, and discusses a project called Commonfare, which is indeed promoting the emergence of a new model of welfare, commonfare, able to support practicable lives in the contemporary stage of digital capitalism. It is therefore a case of PD dealing with institutioning, focusing not only on the microscale of situated projects, but connecting to wider political and economic concerns. Following up on these premises, the questions these paper is trying to answer are the following: What is the relationship between PD practices nourishing the common and institutioning? How does PD supporting autonomous, bottom-up, initiatives intersect existing and new institutions? How can PD participate to institutioning the common?

To answer these questions, the paper is structured as follow: first, we will review PD literature, showing how the initial concerns of $\mathrm{PD}$ as a practice embedded in class struggle can be updated in the light of contemporary society, especially looking at institutioning; second, we will describe how the proposed model of welfare institutions, Commonfare, is itself a potential response to the ongoing societal transformations; third, we will describe the PD project we are engaged in, Commonfare, and how this is responding to the described transformations as a form of institutioning the common; finally, we will discuss what Commonfare as a project suggests in terms of PD practices when focusing on institutioning and nourishing the common, and point toward what lies beyond regarding design.

\section{FROM PARTICIPATORY DESIGN TO INSTITUTIONING THE COMMON}

Participatory Design is traditionally concerned with the politics of technology, although this concern has been declining since the turn of the century, both quantitatively and qualitatively. Quantitatively, Halskov and Hansen [17] showed how papers presented at PDC with an explicit interest in politics declined while, qualitatively, Simonsen and Robertson introduction to the Participatory Design Handbook [9] framed the politics of PD as a concern for people having a say on the technologies they would later use. The goal of this section is to provide a historical review of how $\mathrm{PD}$ research engaged in politics is indeed equipped with theoretical concepts and interesting cases to advance the understanding of the politics of technology. It is a matter of going beyond a conceptualization of it as an action on the technology itself to actually see the politics of technology as something even aiming for perspective of social transformation able to go "beyond capital" [16]. This effort resonates with attempts in neighboring fields, like Human-Computer Interaction, to discuss the politics of technology, for example in relation to environmental sustainability [18], solidarity in contemporary social movements [19], or the grand challenges contemporary facing society [20].
Looking at the origin of PD in the late 1970s - early 1980s in Scandinavia, one particular aspect of the politics of PD is brought forward as a key point: PD was seen as an "offensive strategy" that the trade unions could embrace in the capital - labor conflict [21]. Such offensive strategy - aiming at shaping technologies and, at the same time, the panorama of Nordic industrial relations was combining system development with sociological inquiry on development itself with, in the case of UTOPIA, the goal to establish a trade-union run center on technology itself [21]. Embracing the collective resource approach, researchers at the time were directly engaging with the social and political reality of the factories [22]: the social dimensions of technologies, as well as a strong connection between system design and the political economy of the Nordic countries were at the forefront. Therefore, PD at its origin was dealing with the existing institutions, proposing new ones, and engaging with the political economic conditions.

Since then, the workplace - the site of initial concern for PD - has changed in the light of the transformations in the mode of production toward post-fordism as summarized by Greenbaum [23]: distributed workplaces slowly replaced centralized organizations; flexibility was deemed as more important than economies of scale; temporary agreements and partially re-integrated labor substituted jobs-for-life and rationally divided tasks; individual/group responsibility in a flatter structure became more relevant than closely supervised hierarchies; communication, information, and distribution were the main technical components, instead of the automation of sequential, product-based flows. PD found itself with new challenges ahead, expressed in research by concepts like "PD in the wild" [24], pointing to ways of doing PD in the context of post-fordist organizations.

The renewal of PD research and practices in the 2000s was not limited to an understanding of a renewed workplace, but also to an extension of PD practices toward new domains, what later on Huybrechts and colleagues [14] considered as "the public realm". Such expression, as well as community-based PD [25], reflect the concept of PD going beyond the workplace to actually deal with social groups different from workers, extending PD's reach to social dynamics and conflicts that go beyond the introduction of digital technologies in the workplace. The list of examples collected by Di Salvo and colleagues [25] converges toward participatory design practices in a close relationship with locally-based communities, in which people are defined by their physical location, or interest in a topic, more than by their professional role.

This new direction in PD does not exhaust itself looking at local communities, as exemplified by the accent on nation-wide issues that characterize the work by Clement and colleagues [26]. Dealing with the theme of mass-surveillance and the organization of a contemporary relevant practice like the digitalization of identity documents, they outline how probes, mock-ups, and prototypes can become relevant instruments for PD willing to raise awareness on the issue at stake. The connection between issues, $\mathrm{PD}$, and the formation of new social aggregates is at the center of Christopher Le Dantec's work [27], who describes how PD can bring to the formation of publics, groups of people concerned with the same issue, through the unfolding of different forms of attachments - affective bonds between people, the issue at stake, and a design project. A design project conceptualized in such a way can, moreover, look at 
the forms of engagement of people as "recursive" [28], when the concerns for the issue and attachments to the design project can bring to a renewed attention for the object of design itself, turning potentially into a new institutional form, a digital commons. Therefore, PD looking beyond the workplace has already elaborated some concepts to deal with existing institutions or power relations in society, even proposing new ones.

Dealing with the public realm and social issues, in fact, requires an understanding of existing institutions of potential change and of the possibility to build new institutions. Huybrechts and colleagues [14] have summarized this renewed attention to institutions through the concept of "institutioning", intended as a way to promote ways to engage with institutions and build new relations in the complexity of the contemporary world. Huybrechts et al. [14] mainly refer to institutioning as a way of acting on three forms of what they refer to as "institutional framing", inspired by the work of Castell [29]: the "metacultural frames" refer to broad societal concerns and the role of institutions in them, the "institutional action frames" refer to the way the actions of institutions are described by institution themselves, and the "policy frames" refer to the way institutions are framed in more operational kind of documents, as policy guidelines, etc. In their work, Huybrechts and colleagues point out how there could be three strategies to discuss institutioning as institutional change: as a gradual process of change of existing frames; as a complement or challenge to the actual frames; as a way of giving form to new institutional frames. In this context, Huybrechts and colleagues introduce four points of attention for contemporary PD: 1) considering PD projects as not only micro- and local, they are institutions-dependent; 2) recognizing institutional dependency shows the potential for PD processes to effect institutional change; 3 ) institutioning in PD requires constant movement among the different levels; and 4) the focus on institutioning allows for evaluating PD processes in the light of their relation with institutions themselves.

Teli et al. [11, 13] have argued that a promising political agenda for contemporary PD, updating the one of UTOPIA and the fordist mode of production, could be the one of "nourishing the common", in which the common is defined as the ensemble of the symbolic and material elements that tie together human beings [15]. As discussed before [12], the common can be nourished or dispossessed, that is turned into a source of wealth for the already rich and powerful, and the agenda of nourishing the common aims at favoring social collaboration instead of the dispossession of the common. In the contemporary phase of capitalism, in which life itself is turned into value [30], nourishing the common becomes a potentially promising agenda for PD not focusing only on the workplace [11, 13]. The practical means through which this can be achieved are sketched out in their general terms by Teli, Di Fiore and D'Andrea [11, 13] who identified four potential strategies for PD nourishing the common: 1) to identify an arena of action that is consistent with the possibility to promote societal transformations; 2 ) to clarify what the social groups involved in such an arena are and how they can be connected to nourishing the common; 3 ) to promote an open ended design process in which participation is ready to be overtaken by other actors; 4 ) to find a way to discuss and evaluate how the conditions of the participants gets improved.
In the changing society and PD agenda we have described, the focus on institutioning becomes more and more relevant, especially the one on supporting the emergence of new institutions, being it the construction of "middle element", an institutional element safeguarding and promoting PD [31], or the effort to co-construct autonomous practices with social groups more affected by the transformations of contemporary capitalism [12]. Such a political agenda has the potential to intersect other ongoing research and activist initiatives, like that of promoting the commons as a form of management of shared resources (briefly discussed in PD by Marttila et al. [32], and Teli et al. [28]) or the agenda for "platform cooperativism", in which alternative models of ownership of digital platforms based on workers' control are proposed [33]. The commons and cooperative movements add an institutional character to the effort of PD of granting people control on the technologies they are going to use [9] and therefore constitute a promising perspective to combine the possibility of "nourishing the common" with "institutioning". We refer to this potential combination of the approaches as "institutioning the common", as a way to refer to the aspects of PD processes that contribute to the emergence of new institutions nourishing the common. The goal of this paper is to discuss a project - Commonfare - by explicitly combining institutioning through $\mathrm{PD}$ practices and the agenda of nourishing the common. What is the relationship between PD practices nourishing the common and institutioning? How does PD supporting autonomous, bottom-up, initiatives intersect existing and new institutions? How can PD participate to institutioning the common? The remaining part of the paper will try to address these questions.

\section{COMMONFARE, AN AGENDA FOR RENEWING WELFARE IN CONTEMPORARY CAPITALISM}

Following the suggestions of Teli et al. [11] on PD nourishing the common, we first focus on identifying what could be a transformative social arena, including the three institutional frames considered by Huybrechts et al. [14], metacultural, institutional action, and policy. To do that, we need to briefly recall the history of the last forty years, or what we can call the emergence of neoliberalism. With neoliberalism, we refer to what David Harvey defined as "a theory of political economic practices that proposes that human well-being can best be advanced by liberating individual entrepreneurial freedoms and skills within an institutional framework characterized by strong private property rights, free markets, and free trade [...] Deregulation, privatization, and withdrawal of the state from many areas of social provision have been all too common" [34, pp. 2-3]. Following this we position our work in a historical period in which, driven by a neoliberal metacultural frame, institutional action is confined to setting the stage for free-markets and policies that are those of deregulation and privatization.

From the point of view of people's everyday life, what political economy refers to as social reproduction in the light of Karl Marx's work $^{1}$, the emergence of neoliberalism has meant a reduction of

\footnotetext{
${ }^{1}$ Social reproduction in Marxian terms refer to all the activities that are necessary to ensure the reproduction, biological and cultural, of the workers. This includes, for example, education or, as highlighted by feminism, care.
} 
public services, welfare state redistribution first of all, and an increase in social inequalities [35]. The neoliberal period has been characterized, moreover, by the strengthening of financial markets through specific technological infrastructures, constituting both the conditions for the interconnection of the global centers of financial activities [36] and the possibility for the emergence of new financial products, as derivatives and credit default swaps, that have been central in the financial turmoil that started in 2007 [37].

In this period, digital technologies have been relevant for another reason: they allowed for the quest of new forms of capital accumulation, what we can refer to as "platform capitalism" [1], in which corporations in the digital domain provide capital with new possibilities of valorization ${ }^{2}$. More specifically, these new forms of accumulation are based on three coexisting processes: 1) the process of heteromation [38], in which digital technologies weaken labor and discipline it, often requiring free labor to allow the unfolding of digitally mediated practices; 2) the transformation of people using digital technologies, social media in particular, into a specific kind of commodity, the "audience commodity" [39], sold to investors through the quantification of social relations [40]; 3) the use of all the data collected on workers, customers, or users, as a form of intra-capitalist competitive advantage [1].

The role of digital technologies is crucial, but should not be overestimated as other factors are contributing to the form of contemporary capitalism, such as, for example, the extension of intellectual property rights, the manipulation of genes and the strong relevance of biotechnologies. Taken together, these elements contribute to capital accumulation on the basis of the commodification of life, human, animal, and vegetal, in what Morini and Fumagalli define as the "life theory of value" [30]. Social and ecological reproduction becomes, in such a way, the basis for processes of wealth accumulation and the arenas in which contemporary exploitation is taking place.

This is visible in the domain of the welfare state, in which the emergence of the "workfare" model has subordinated access to public resources to forms of free labor by the recipients of welfare itself. In this context, some economists are proposing a new model of welfare provision that recognize the centrality of social reproduction and the contribution that people's lives provide to contemporary capital accumulation with life itself, what is called 'Commonfare'. Commonfare, as a model for contemporary welfare, includes: access to healthcare and education, considered central elements for social reproduction, along with access to open and free cultural resources, considered as central productive factors in contemporary society; an unconditional basic income, as a form of wealth distribution recognizing the centrality of people lives in contemporary economy beyond a job-based society; and currency sovereignty, even at the local level, as a way of managing income distribution [41, 42].

Commonfare, as a concept for welfare provision as well as a political agenda, combines and expands the institutioning frames: first, it articulates changes at the metacultural level, suggesting a way forward beyond the free-market ideology of neoliberalism and

\footnotetext{
${ }^{2}$ Valorization, in Marxian terms, refers to the process through which capital see its value increased. The process of valorization in industrial capitalism takes the famous form money-commodity-money1, in which the production of commodities is the mean through which money1 is bigger than money.

its harshness on the unemployed or other welfare beneficiaries; second, it identifies a new space of institutional action, suggesting that institutions favor human flourishing instead of disciplining human life; third, it identifies specific policies, as a universal basic income or open access to cultural and knowledge resources; and fourth, it expands the domain of institutioning including directly political economy and wealth distribution and redistribution.

From the point of view of the design of digital technologies, fostering Commonfare as a welfare model means to align with a perspective of PD nourishing the common, in different ways: first, it considers income distribution as a key arena of contemporary society; second, it acts beyond the workplace to intercept the social groups most affected by contemporary inequalities, as welfare recipients or people excluded by the shrinking welfare safety net; third, it recognizes the centrality of social reproduction and the need to work toward new institutional forms that extend beyond the design process and the presence of the designer itself; fourth, it provides a baseline, that is people's everyday life, to be investigated as the starting point for the evaluation of a design process. All these aspects are presented in our empirical case, the Commonfare project, on which we will focus from now on.

\section{THE COMMONFARE PROJECT}

The Commonfare project serves as a case of participatory design, seeking to respond to societal challenges within the European Union relating to precariousness, low income, poverty and unemployment. The goals of the project relate to reducing these risks of social exclusion and poverty, which currently accounts for almost $24 \%$ of the population of the European Union [43]. In particular, the goal is to build a web-based platform - commonfare.net - to provide: (1) improved accessibility of welfare state provisions and policies; (2) storytelling tools to connect people and groups engaged in bottom-up welfare practices; and, (3) support for the most promising of bottom-up welfare practices with a view towards scaling up to national and European levels. The Commonfare project is being piloted in three countries - Croatia, Italy and the Netherlands - with a number of at-risk populations: unemployed youth (Croatia), precarious workers (Italy and the Netherlands), non-Western migrants (Netherlands) and freelancers (Netherlands).

The basis for the Commonfare project is a welfare model of the same name we describe in the previous section, and the goals of responding to societal challenges by providing an alternative to Keynesian public welfare, and 'workfare' institutions by championing universal basic income and the management of the commonwealth and common goods, are reflected in the approach. As part of the platform and technology design, and in a way to support bottom-up good practices, the project is exploring the use of crypto-currencies to address the concept of basic income. The positioning of this model of Commonfare within the project is shown in Figure 1, in which: 1) the digital platform designed, commonfare.net, looks at the "Collective Awareness and Collaborative Practices beyond GDP" (part of the lexicon of the funding agency, to suggest the use of digital technologies to promote collective action [44]); 2) the project (called PIE News at proposal time) interacts with municipalities, local communities, and the state; 3 ) to foster Commonfare as a welfare model; 4) bringing to the emergence of new institutions 


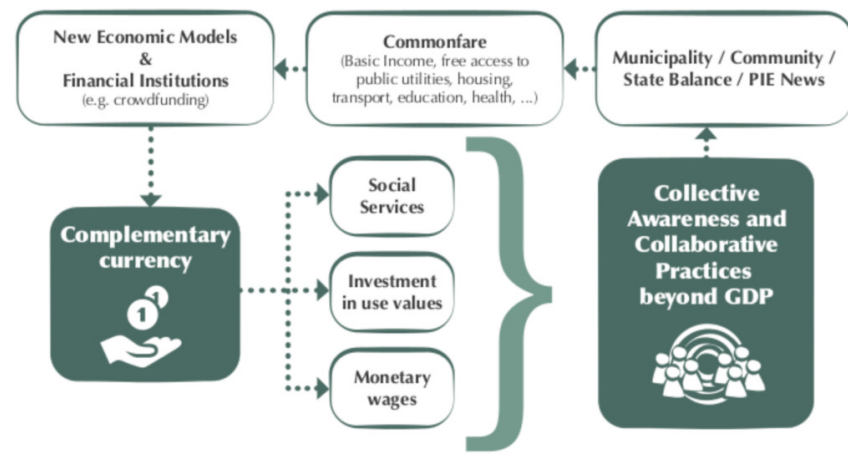

Figure 1: The Commonfare economic model of the project according to the accepted project proposal.

and economic models; 5) including a complementary currency supporting social services, wages, and investment in use values $\left.{ }^{3} ; 6\right)$ in an iterative and recursive way.

The project is being carried out by a heterogeneous and interdisciplinary consortium of eight organizations - three academic institutions (two universities and one research center), two technical (software development and research non-profit) and three pilot (local NGOs in each pilot country) partners. The pilot partners represent a diverse group of organizations, and includes a social art project, an anti-discrimination and socio-economic equity advocacy group, and an association promoting basic income. The consortium collaborates in the design and development efforts towards the platform, as well as the non-technical aspects of the project - such as the establishment and fostering Commonfare by engaging with local businesses and community groups, as good practices that respond to the societal challenges of the project towards new welfare institutions. This blending of institutional and technical outcomes of the project are described by Botto and Teli [45] as "public design", and the technical platform to be understood as a "digital commons" [28]. More in detail, following Teli et al. $[11,13]$, the open design process enacted sees the NGOs doing empirical activities as fieldwork (including focus groups, interviews, workshops) with the support of the designers. The project design approach, as well as the tensions and negotiations involved in such a project, have previously been discussed focusing on the role of PD practitioners in the process of designing digital tools fostering commonfare [46].

We draw on a number of reports and documents as empirical data to support our presentation of the different types of institutioning that takes place as part of the Commonfare project. Internal documents include: design workshop reports (from activities conducted with research participants), minutes of general assemblies (whole consortium), reports from focus group self-evaluation (conducted with consortium partners), design workshop plans (between consortium partners), low and high fidelity mockups, the consortium

\footnotetext{
${ }^{3}$ In the Marxian tradition, use value is the value of objects from the point of view of social reproduction and collective use, while exchange value refers to the price at which objects are exchanged. For a more extensive treatment of the concepts of value in Marxian terms from the perspective of contemporary computing, social informatics and PD, see Hakken et al. [16].
}

mailing list, and an internally developed glossary. External documents include: The project grant agreement, project deliverables (such as work package reports), informational materials (factsheets, press releases, project flyers), advertisement for local events, and the developed platform Commonfare.net. From these we categorize the work and empirical data in terms of different types of existing institutions we engage with, and that which support and lead to the design of Commonfare as a new institution.

\subsection{Relations with existing institutions}

Regarding existing institutions, we further make the distinction between the international - be it transnational or at a European level - and local - focused on the engagement of pilot partners with different local communities.

4.1.1 The establishment of the Commonfare project, and the project's relationship with the European Commission. The establishment of the Commonfare consortium and project was favored by the existence of a particular institutional funding line called CAPSSI (Collective Awareness Platforms for Sustainability and Social Innovation). According to the official website, CAPSSI is an initiative promoted by the European Commission and located within within the H2020 framework programme which "aims at designing and piloting online platforms creating awareness of sustainability problems and offering collaborative solutions based on innovative networks of people, ideas, services and technologies enabling new forms of social innovation", supporting "environment-aware efforts, grassroots processes and practices to share knowledge, achieve changes in lifestyle, production and consumption patterns, and set up more participatory democratic processes on a global pan-European scale". The CAPSSI emphasis on interdisciplinary and transdisciplinary collaboration in order to confront social issues and to promote participatory democratic processes, therefore, represented a favorable institutional frame for a project like Commonfare. This is because Commonfare is deeply informed by an interdisciplinary approach and which clearly aims to pursue political goals such as the emergence of a new model of welfare based on the common.

The Grant Agreement between the European Commission (EC) as an institution and the project consortium represents a development of the CAPSSI frame from which the consortium, project and research take shape. The agreement also serves to establish the bounds by which the project will be judged in terms of its successes and failures. These bounds, therefore, serve to regulate the relationship between the consortium and the funding institution and to let dynamics of power emerge in some circumstances. After the ratification of the official agreement between the EC and the consortium, there have been multiple occasions of interaction via the project. For example, an aspect of the grant agreement is the specification of a series of project milestones for when significant work package reports must be submitted, and when certain technical deployments must occur. Following a general assembly at the one year mark of the project, the consortium made a request to postpone two of these deadlines - one regarding the submission of a project deliverable and the other one regarding the second release of the platform - while the postponement of the project deliverable was agreed by the EC, the request to postpone also the second release of the platform was denied, notwithstanding the 


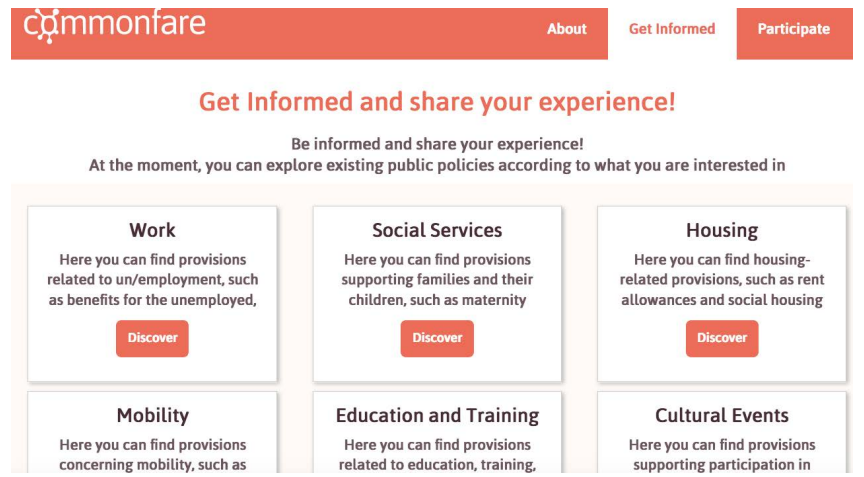

Figure 2: The categories of welfare provision available on the platform.

negotiations that project coordinators put in place. So, in respect of an official agreement that set up clear bounds between the EC and the consortium, there was a certain margin of flexibility achieved by a relation of trust between the two parts, but also a certain degree of rigidity (in the case of denial) typical of any bureaucratic body. Keeping a balance between the rules and conditions characterizing any contract with funding agencies and the flexibility and openness that any participatory design project entails is precisely a source of friction that needs to be managed at every step of the project.

4.1.2 Frame of Institutional Welfare Provision. Given Commonfare as research project that ultimately aims to foster a new model of welfare, one of the first institutional relations that the whole consortium set up was the one with the current state of political economy in Europe. Specifically this has focused on the welfare policies applied in the three pilot countries and the welfare state provisions available for welfare recipients. At a trans-national level, the different pilot partners sought to understand the way in which the welfare state provisions - a product of both local and national institutions - have evolved over the recent history of their respective country, with the goal of then sorting them into a common set of categories. This was shaped by the goal of designing a single technical representation that could present the options in a consistent way, within the design of the first release of commonfare.net, and in Annex 1, 2 and 3 of a project deliverable [47]. The construction of a detailed database of information of the existing institutional welfare measures in the three pilot countries was indeed the goal of the first release of the platform, which now carries such information divided into six categories: work, social services, housing, mobility, education and training, and cultural events (see Figure 2).

However, the point of departure of the Commonfare project, and the very elaboration of the concept of 'Commonfare' [41, 42], is the recognition of the insufficiency of the current welfare system, which is unable to confront the global economic and financial transformations that are leaving a growing number of people in condition of precariousness. A case in point is the Participation Act implemented in The Netherlands in 2015, a welfare measure that replaced previous, more inclusive policies which supported people experiencing difficulties in finding a job and have no other means of income or equity capital, or that supported people (partly) incapable of work due to a mental or physical disability; the Participation Act has therefore: "further tightened the conditions under which citizens can rely on the social safety net and claim benefit" [47]. Another example is the exclusive social security system in Croatia, which is historically opaque as it favors certain interest groups such as war veterans, besides holding a a social expenditure that lies well below the EU28 average [47]. These are just two examples that unveils a sort of ambivalent and frictional relationship that takes place between the project and the existing institutional welfare policies: if, on the one hand, it is recognized the utility of the current welfare state provisions - although inadequate to cover the emerging needs of people living in precarious condition - on the other hand Commonfare was born to foster a new model of welfare that is already in place at local level.

4.1.3 Dutch pilot partner engaging with municipal councils. As Commonfare is a research project that depends on a strong pilotstrategy in order to foster public engagement, therefore ensuring the participatory design and sustainability of the platform, pilot organizations are deeply committed towards the construction of trust relations with both target populations and institutional actors. Starting from the first platform release, pilot partners have indeed begun to disseminate the project within local municipalities and to cultivate meaningful relationship with local institutional actors. The Dutch pilot, for example, has been particularly active in this respect as it was able to initiate meaningful relations with institutional (being them universities, trade unions, municipal councils, and NGOs) actors in the three municipalities covered by the project: Amsterdam, Rotterdam, and The Hague. This presence on local territories has been certified by the opening of two "Commonkiosk" in the cities of Rotterdam and The Hague. Each Commonkiosk is a physical space in which the Dutch pilot organization is working one day per week in order to provide information about Commonfare, help people who are seeking information about existing welfare state provisions, and build relationships with local institutions. One of the most meaningful events in this respect has been an event organized in The Hague with the collaboration of the local target population (non-Western migrants, mostly women), in which Commonfare was introduced to the mayor of the city. In this respect, the relationship between the Dutch Commonfare pilot and existing institutions (like municipalities) appears to be the least frictional because of a general good disposition of Dutch local institutions towards the claims raised by the project.

4.1.4 Croatian pilot partner and difficulties with local municipalities. A different relationship links the Croatian pilot with institutions. Our local organization in Croatia is indeed a well known national civil society organization which works at the nexus of public policy research and advocacy for the promotion of peace, anti-discrimination and socio-economic equity, supporting individuals and initiatives in these goals at the grassroots level. The highly public exposure of the organization towards sensitive issues, together with the cultural and social background of a country that appears to be devoted to conservatism in its politics and values, has always constituted a trouble for the construction of trustful relations with institutional actors. This difficulty was made clear during a self-evaluation focus group undertaken by the consortium (July 2017), in which they explained the presence of a hostile political 
environment in the country that is working against left-like issues and associations; as a consequence, our Croatian pilot expressed troubles in dealing with the current situation that is due to of a mix of government hostility and cultural habits of local people, reiterating, at the same time, its intention of reaching out to institutional actors, both at the local and at the national level. Contrary to the Dutch case, the relationship between the Croatian organization and existing institutions, both at national and local level, appears uneasy because of the substantial divergence between the mainstream political culture of the country and the political claims and values advanced by the Commonfare project.

4.1.5 Italian partners and local municipalities. The Italian pilot organization is an advocacy group whose main focus of action is the dissemination of awareness about the issue of basic income among policy-makers. They are comprised of activists and researchers, mainly based in the cities of Rome and Milan. In addition, their members have solid connections with left-wing social movements and with some members of the left-wing political parties, who participate in some municipal governments in Italy. This is highlighted at a recent Commonfare dissemination event, organized by the Italian pilot (October 2017) in the city of Milan, which saw the participation of two councilors who seat in the local city council and who are in charge of social policies, labor and economic activities. These two institutional actors took part in this event with interesting talks that underlined the need to experiment with new tools and forms of welfare (despite budget constraints), and the importance to test and support various forms of social innovation - such as Commonfare - as a value and a local policy that can be exported to other Italian and foreign contexts. These events organized with the participation and collaboration of local institutional actors constitutes an important pillar of the sustainability issue, which will be discussed - among other things - in the next section. Against this backdrop, the Italian pilot seems driven by a strategic vision that aims to promote Commonfare among mainstream institutions, while being aware of the frictions and the tensions between the political culture that animates Commonfare and the set of beliefs and practices that characterize the mainstream political agenda.

\subsection{Towards New Institutions}

As it should be clear up to now, Commonfare is a design project that is not only dealing with existing institutions through dialogue, mutual support, and challenge to the status quo, but also a project interested in establishing new institutional forms, what we refer to as "institutioning the common". In this section, we will describe such efforts in building new institutions, starting from two different processes that are at play while doing it: 1) Commonfare is supporting locally-based small organizations, formal and informal, in their capacity to build networks and alliances, as well as to scale up to the European level when appropriate, and 2) Commonfare is contributing to the emergence of completely new institutional forms, as a way to actually accomplish the goal of supporting the previously introduced local initiatives.

The local initiatives we are talking about have been collected by the partners conducting fieldwork in Croatia, Italy, and the Netherlands, and they include examples of critical consumption groups, community gyms, housing initiatives, education and training, employment initiatives, healthcare, food saving and provision, government watchdogs, ethical banking, homelessness, clothing, energy, crypto-currencies, and basic income provision [47]. Taken together, they reflect bottom-up answers to the needs of the population the project is involving in its activities, consisting of precarious workers, non-Western migrants, single parents, and others who have been disadvantaged by the transformation of contemporary capitalism and by the effect of the financial turmoil originated in 2007 [47]. For this reason, the Commonfare project is looking at this diverse ensemble of practices and initiatives as forms of bottomup welfare, as they try to articulate answers to daily issues even beyond what is considered the traditional domain of the welfare state, as unemployment or cash transfers to specific population. To reflect the articulation of the problem by the partners in charge of the empirical research on people's needs and bottom-up initiatives, these initiatives contribute to the "practicability of life", as one of the project partner defined actions of these local initiatives.

These bottom-up initiatives are all based on forms of alternative economy, social bonds and cooperation on the basis of the principles of reciprocity, solidarity, and sociality. In describing these experiences, pilot organizations claim that they "place themselves outside of the institutional political arena, and nevertheless they have the ambition to bring about their own political vision which is outside the closed universe of private property and within the open space of what are called "the commons" [47, p. 75]. These bottom-up welfare experiments - that in the context of the Commonfare project are defined as "good practices" - are an expression of local circumstances and specific of the community they belong to. The heterogeneity of their specific interests and the social, geographical, economic difference between the three countries in which they take shape make difficult to outline a clear definition; however, the empirical research and field activities have allowed pilot organizations to identify some criteria according to which these good practices become particularly worthy in terms of social significance: 1) effectiveness (in terms of achieving the goal set); 2) sustainability (in terms of financial and management autonomy); 3 ) innovation (in terms of meeting and adapting to the initial need); 4) reproducibility (in terms of the ability to reproduce them in similar context); 5) transferability (in terms of possible use in different context and sectors).

4.2.1 Fostering solidarity among people experiencing precarious conditions. The criteria of reproducibility and transferability play a crucial role in the unfolding of Commonfare as a project and commonfare.net as a digital platform. In fact, such criteria are the backbone of the effort of the project to go beyond the forms of "exclusive solidarity" that emerged during fieldwork [47]. With exclusive solidarity, we refer to the possibility that the already listed practices, and other similar bottom-up initiatives, promote solidarity among groups of similar people, ending up in further exclusionary boundaries. As a design goal of Commonfare is to promote solidarity on a large scale, especially among people in the different countries involved so far, the risk of exclusive solidarity is a relevant one, and the aforementioned criteria of reproducibility and transferability are part of one key component of commonfare.net: the capacity of narrating and sharing stories. The overarching goal 
of this digitally supported capability is indeed to favor the reproduction and transfer of the good practices through the dissemination of stories on their coming into being and their positive effects on the life of people. To put it simple, people concerned with specific issues can and will find on commonfare.net stories on how other people somewhere else have collectively addressed the same issues and, in this way, be inspired in their daily activities.

In the contemporary social media landscape, a similar effort could look like those practices - such as the creation and sharing of content - that other digital platforms favor; nevertheless, our empirical work points to the conditions through which such effort could have value, not only despite existing platforms, but because of them. This can then serve to highlight the attributes of digital platforms that support bottom-up institutioning. For example, in the fieldwork done thus far, the participants in the local contexts have expressed forms of distrust towards current social media, as one of the participants said "I want to be in control of what I share with whom or not, and not everybody is privileged to look into my life, because I do not trust Facebook [...] If I trust the relationship and the platform where this information goes [...] then I am willing to open up more".

Trust, according to our empirical results, can be built around avoiding stigmatization or stigmatizing processes (that imply, for example, to exclude typical information from individual profiles such as gender or ethnicity), and be careful with the management of data collected through the platform. One of the implications of these results has been reinforcing the openness of the content shared through commonfare.net, protected by a creative commons, non commercial, share alike license. That reflects the goal of the Commonfare model to support access to knowledge as well as its protection from practices of appropriation and exploitation. This was not the only and the biggest implication. Indeed, one of the main results of social research has been that of re-thinking what in the project proposal was intended to be a rather mainstream reputation system into a completely different evaluation of the contribution people provide to commonfare.net; as results suggested, such evaluation system should avoid disciplining individual behavior and it should instead evaluate positively the capacity to contribute to the overall health of the social environment measured through social network analysis techniques [48]. In the new institutions promoted by Commonfare, trust is therefore based on the contribution to the overall collectivity more than on the assessment of individual micro-practices, and the institutions themselves are strengthened by social collaboration.

4.2.2 Experimentation with a complementary currency within future releases of commonfare.net. Supporting the production and sharing of stories about interesting bottom-up practices is not the only way through which commonfare.net is going to foster the emergence of Commonfare as an economic model. Another way the project is promoting social collaboration is through the implementation of a digital currency that will achieve two main objectives: 1) to provide a basic income to participants to commonfare.net; and 2) to favor economic transactions among people and, in such a way, the financial sustainability of collaborative practices. The overarching goal is to allow for a virtuous economic cycle - enacted by people for people as in the anthropogenic model described before - to emerge and to be funded through forms of monetary sovereignty, although in the domain of a complementary currency and not in the context of fiat money (e.g. Euros, Dollars, etc).

As an institution, forms of complementary currencies come with specific set of requirements, tensions, and relations with the existing world, and that emerged clearly in the work conducted for the Commonfare project, both at the level of economic reasoning and at the level of empirical encounters with participants, all elements well detailed in the project deliverable discussing reputation and currency [48]. The main poles of the identified tensions concern the potential exchange of the crypto-currency in fiat money; the exercise of monetary sovereignty and capacity to scale in terms of adoption and diffusion; and the control over the currency supply. Those are all socio-technical issues, as they also relate to specific implementations of the blockchain technology, but here we will discuss their social and institutional aspects.

First of all, the exchange in fiat money is one key tension, as exchangeable currency can turn the circulation of a complementary currency as part of the institutionalized economic cycle, and that has two main consequences: 1) an exchangeable currency could favor initiatives oriented toward its simple accumulation, instead of promoting its circulation inside commonfare.net; 2) a non-exchangeable currency, willing to bring relief to the life of people, needs to be inserted in contexts wherein obtaining it and spending it bring benefit to people. This is a problem of different economic incentives. Second, any digital currency comes with its own governance rule, and the more independent a currency is the higher the control the ones supporting and using it can exercise over the currency itself; on the other side, a completely independent currency has issues of scalability, as its adoption can be limited only to the ones who control it, while adopting a currency already in use can help increase its adoption and relative value (sometimes even through speculative mechanisms, another aspect of the tension). The tension between sovereignty and scalability is therefore a tension between self-management and openness to social forces beyond the control of the designers and managers of the currency. That is related to the tensions of the currency supply, a crucial economic factor since it can determine the level of a basic income, and inflation rates: a completely autonomous currency or a currency with an high level of control by managers can allow for high and adjustable currency supply, while existing currencies follow supply dynamics that are external and hard to control. To accommodate the different needs of the local groups involved by the pilot partner, the Commonfare project is now implementing different combinations of the tensions which were highlighted as crucial aspects in the research so far [48, p. 38].

4.2.3 The issue of sustainability beyond the research funding. The different efforts accounted for so far are all oriented toward the ambition of one final result: to build something technologically and institutionally able to be sustainable beyond the end of the research funding. That entails not only to find out capable and interested people to be involved in the complex use and governance of commonfare.net (including the digital currency), but also to involve existing institutions like policy makers, trade unions, and NGOs, in order to build up the conditions for sustainability. Such effort is needed due to certain conditions encountered during fieldwork. 
First, some of the good practices identified in the different pilot sites operate in a gray area - between autonomous social collaboration and institutionalized rules - and therefore they could need forms of institutional coverage and support in compliance with existing (or new) set of rules. This implies that supporting good practices in the long-run also means contributing to the reshaping of existing institutions in a way that supports the flourishing of the bottom-up practices identified. Second, the construction of a meaningful economic cycle can be strengthened by the acceptance of the commonfare.net currency by existing actors like public administrations or service providers. Third, only the maintenance of commonfare.net, not to mention further design and implementation, could require some financial support on the side of existing organizations.

In this context, the effort of building a distributed structure of support alongside existing organizations is not trivial, and expands the boundaries of what is usually conceived as a design project. It is for this reason that, since its inception, the Commonfare project foresaw a necessary effort in communication and dissemination - involving the organization of more than twenty events directly funded by the project - as means toward a stronger engagement of participants and existing institutions. At the moment of writing, the project is at the beginning of its activities specifically devoted to promote sustainability (following the leadership of one of the pilot partners), therefore we can only anticipate the challenges ahead, pointing to the fact that such challenges are not strictly related to traditional technology design but to a wider constellation of skills and practices.

\section{DISCUSSION}

Thus far, we have presented how recent developments in PD relate to the history of the field in their goal to expand the scope of PD projects toward institutions and a new political agenda for $\mathrm{PD}$ practices. In particular, we have discussed the Commonfare project by framing it as a case of "institutioning the common", that is how the political agenda of PD nourishing the common [11-13] intersects institutioning as part of PD processes. Following Huybrechts et al. [14], we have presented the project as intersecting the political agenda of nourishing the common in four different ways: promoting changes at the meta-cultural level, identifying new spaces for institutional action, advocating for specific policies, and including political economy in the reasoning on institutioning. That has translated in specific research questions, as mentioned earlier: What is the relationship between PD practices nourishing the common and institutioning? How does PD supporting autonomous, bottom-up, initiatives intersect existing and new institutions? How can PD participate to institutioning the common?

A project like Commonfare, with ambitions to connect the local level of pilot actions and participatory design in the different countries to a European wide level, helps answering these questions from the situated perspective of such an ambitious project. In fact, the goal to propose and support a new economic model, already visible in the local contexts but still in fieri from a wider perspective, helps to highlight some of the aspects of the process of institutioning the common that are our focus.
First, following the intuition of those arguments that outline a way to go "beyond capital", the emergence of new values not necessarily connected to quantification [16], Commonfare suggests that "new institutions to support new values" are necessarily intertwined: such entanglements between institutions and values is described by the Commonfare economic model presented in Figure 1 and by the inclusion of healthcare, education, open access, monetary sovereignty, and basic income [41, 42]. Second, Commonfare nourishes the common in fostering solidarity among people excluded, or partially excluded, by contemporary institutions and it does so favoring transferability and reproducibility of practices already nourishing the common. The process is not frictionless, rather allowing for an understanding of renewed concepts of trust rooted in the contribution to the common itself. The process also exposes the frictions between a social value like trust and the economic aspects symbolized by the digital currency. This last aspect, a crucial element of the commonfare model in terms of sovereignty, has been indeed one of the most critical aspects to design collaboratively due to the different circumstances of the participants in the different countries.

In fact, in comparison to Huybrechts et al. [14], who, in our understanding, describe the process of institutioning as a vertical movement among different levels (culture, action space, and policies), Commonfare as an empirical case suggests that the constant movement is also taking place in an horizontal way, among different institutional forms and the different contexts in which the life of people unfolds. The relations established by the partners working in the field with the local actors, municipalities first of all, is an example of such difference, as well as the different welfare policies available even at the municipal level. In this perspective, PD practices, always careful in representing the voices and perspectives of people, can bring clarity on the relation between the different contexts, and support the emergence of wider perspectives coming from the diversity of contexts. The example of the categorization of different forms of welfare provision in six categories, built combining the expertise of pilot partners and focus groups with participants, is an example of the process of horizontal clarity emerging from participatory design practices connecting to people's everyday life.

The horizontal view is helpful to frame the relations of PD practices nourishing the common with existing and new institutions. First, such angle is able to account for the parallel unfolding of different actions. In relation to existing institutions, we see constraints and resources for the unfolding of PD practices, be they: constrained institutionally in terms of actual grants; the existing welfare provisions as resources to share; or, the different institutional contexts in the three pilot countries as an ambivalent space for the project action. The search for sustainability by Commonfare is a clear example of this double aspect of the local contexts as constraints and resources, as the efforts to engage meaningful actors, being them existing institutions or bottom-up practices, is extremely context dependent and the challenge for PD and it is posing new challenges for the connection among the different localities of the project. Second, the horizontal look helps to conceive the actions of people - what we referred as good practices - as developing in parallel. Moreover, when thinking about exclusive solidarity, 
the goal of the design process to connect the good practices is indeed acting on the assumption of activities going on in parallel that can benefit from crossing each other. The experimentations with a digital currency can also be read through an horizontal dynamic: the multiple tensions unfolding depend on different socio-technical aspects of digital currencies that need to be considered in parallel, and in parallel with the needs of the local contexts. Equally, the goal of achieving sustainability refers to the need of including in the project future existing institutions supporting a potentially new one, even here in parallel. The parallel interplay of these elements is one of the relevant aspects of PD institutioning the common: the continuous, parallel relations, among the different contexts, social groups, and institutional space needs to be considered when planning PD projects oriented to nourish the common, as well as moments of convergence between the parallel developments.

From the final research question - how can PD participate to institutioning the common? -, we see in the case of Commonfare the need of PD practitioners as actors promoting mutual collaboration and trust, in ways that avoid neoliberal disciplining and stigmatization. PD practitioners can then become agents who favor collaboration between diverse practices in different contexts while, at the same time, providing opportunities for replicability and transferability. Working with groups of people already experiencing reciprocity, solidarity, and sociality, and challenging the institutionalized political arena, are indeed ways through which PD practitioners can work toward the construction of new institutions, nourishing the common. This is indeed consistent with the second of the strategies proposed by Teli et al. [11], that is identifying social groups able to bring forward social transformation. Working with existing alternatives to the dominant economic models is one way of enacting such strategy, as suggest also by Vlachokyriakos et al. [19] when describing the need for designers to be active within the social movements they are designing with. Such form of embeddedness favors questioning assumptions of the designers themselves, opening up the space for unexpected results. For example, the emergence of trust enacted in Commonfare - starting from the empirical work - proposes a model of construction of trust as well as connection among people and groups based on perspectives other than those of contemporary reputation systems. At the same time, PD practices with an ambition toward large scale effect are helping to highlight the tensions and obstacles that impact the process of connecting activities proceeding in parallel, as Commonfare discussions on the digital currency testify. In this case, PD confirms to be not only a design activity but also a process of producing knowledge on the social conditions of the design activities themselves [9]. The difference between the tensions in the digital currency case and the homogeneity of views on designing and implementing a platform that does not include exploitative mechanisms (in terms of personal information, as is widespread on most social media) does in fact suggest that some concerns are widely shared among the participants to Commonfare, while the construction of an economic cycle through a currency is a domain where controversies and tensions are still unfolding. That confirms the idea that the interplay between economic aspects and non-monetary values is one of the domains to be further investigated by PD practitioners, as suggested by Hakken et al. [16].
Returning to our three main questions, we argue that PD practices nourishing the common (that is, with an explicit political agenda) intersect institutioning not only through the different vertical levels of institutioning, but also through the horizontal relations among different institutional contexts. The horizontal movement become visible thanks to PD attention to people's lives, which constantly challenges the status quo. The focus on the horizontal dimension is also helpful to respond to the second question as it points to the capacity of PD processes to actually connect different actions undertaken by people going in parallel, including not just the design of artefacts, but also the building of relationships. We advance that those PD practices committed to institutioning the common are not free of tensions or frictions; therefore, we argue that paying attention to those choices that produce tensions, as well as those that are frictionless, serves to produce knowledge on the diverse aspects of social life. In practical terms for commonfare.net, we can draw on the concept of infrastructuring mentioned earlier to, for example, detail the actions of different actors (participants, European commission and partners), highlighting tensions that relate to the use of language [49].

\section{CONCLUSION}

In this paper we have outlined how recent developments in PD, in particular the political agenda of nourishing the common and the analytical perspective of institutioning, can be related through the discussion of the empirical project we are working on: Commonfare. We have indeed defined the convergence of these concepts as "institutioning the common", that is relating with existing institutions and building new ones while engaging in PD processes nourishing the common. The empirical case of Commonfare has served to articulate how the vertical movement between cultural, action, and policy frames, discussed when referring to institutioning, can be fruitfully integrated with a horizontal perspective that shows the interrelation and differences between the different existing institutional domains and potential new ones.

We claim that our argument of "institutioning the common", which takes shape from a large-scale, ambitious project, can contribute to bring forward the discussion on PD, institutioning, and nourishing the common. In order to further enrich such discussion, more work is needed. For example, the multiplicity of domains (technical, sociological, economic, political, ethical) that a project like Commonfare intersects, points to the need to acknowledge the inherent interdisciplinary character of PD. Specifically, the attention given to vertical and horizontal movements that define the process of institutioning requires a more refined theoretical toolbox, for example, by expanding on the influence of socio-anthropological research, which is already a long-standing practice in PD research. Finally, institutioning the common is a promising research area for $\mathrm{PD}$ and, we argue, a compelling political agenda that deserves to be picked up by those projects that aim to address contemporary societal challenges.

\section{ACKNOWLEDGMENTS}

The PIE News/Commonfare project has received funding from the European Union's Horizon 2020 research and innovation programme under grant agreement No. 687922. 


\section{REFERENCES}

[1] Nick Srnicek. 2016. Platform Capitalism. John Wiley \& Sons.

[2] Trebor Scholz. 2016. Uberworked and Underpaid: How Workers Are Disrupting the Digital Economy. John Wiley \& Sons.

[3] Stacco Troncoso and Anne Marie Utratel. 2015. Commons Transition: Policy Proposals for an Open Knowledge Commons Society. Foundation for Peerto-Peer Alternatives.

[4] 2016. Frankfurt Paper on Platform-Based Work. (2016). http:// crowdwork-igmetall.de/

[5] Sandrino Graceffa. 2016. Refaire le monde... du travail: Une alternative à l'ubérisation de l'économie. Editions REPAS.

[6] Charlotte Hess and Elinor Ostrom. 2007. Understanding Knowledge as a Commons From Theory to Practice. MIT Press, Cambridge, MA.

[7] Stavros Stavrides. 2016. Common space: the city as commons. Zed Books Ltd.

[8] Adrien Labaeye. 2017. Collaboratively mapping alternative economies. Coproducing transformative knowledge. Netcom. Réseaux, communication et territoires 31-1/2 (2017), 99-128.

[9] Jesper Simonsen and Toni Robertson. 2012. Routledge International Handbook of Participatory Design. Routledge.

[10] Thomas Binder, Eva Brandt, Pelle Ehn, and Joachim Halse. 2015. Democratic design experiments: between parliament and laboratory. CoDesign 11, 3-4 (Oct. 2015), 152-165. https://doi.org/10.1080/15710882.2015.1081248

[11] Maurizio Teli, Angela Di Fiore, and Vincenzo D'Andrea. 2016. Computing and the Common: An Empirical Case of Participatory Design Today. In Proceedings of the 14th Participatory Design Conference: Full Papers - Volume 1 (PDC '16). ACM New York, NY, USA, 1-10. https://doi.org/10.1145/2940299.2940312

[12] Maurizio Teli. 2015. Computing and the Common. Hints of a new utopia in Participatory Design. Aarhus Series on Human Centered Computing 1, 1 (Oct. 2015), 4. https://doi.org/10.7146/aahcc.v1i1.21318

[13] Maurizio Teli, Angela Di Fiore, and Vincenzo D'Andrea. 2017. Computing and the common: a case of Participatory Design with think tanks. CoDesign 13, 2 (April 2017), 83-95. https://doi.org/10.1080/15710882.2017.1309439

[14] Liesbeth Huybrechts, Henric Benesch, and Jon Geib. 2017. Institutioning: Participatory Design, Co-Design and the public realm. CoDesign 13, 3 (2017), 148-159. http://www.tandfonline.com/doi/abs/10.1080/15710882.2017.1355006

[15] Michael Hardt and Antonio Negri. 2009. Commonwealth (1 edition ed.). Belknap Press, Cambridge, Mass.

[16] David Hakken, Maurizio Teli, and Barbara Andrews. 2016. Beyond Capital: Values, Commons, Computing, and the Search for a Viable Future. Routledge, New York, NY. https://www.routledge.com/ Beyond-Capital-Values-Commons-Computing-and-the-Search-for-a-Viable/ Hakken-Teli-Andrews/p/book/9781138924444

[17] Kim Halskov and Nicolai Brodersen Hansen. 2015. The diversity of participatory design research practice at PDC 2002-2012. International fournal of HumanComputer Studies 74 (Feb. 2015), 81-92. https://doi.org/10.1016/j.ijhcs.2014.09.003

[18] Paul Dourish. 2010. HCI and Environmental Sustainability: The Politics of Design and the Design of Politics. In Proceedings of the 8th ACM Conference on Designing Interactive Systems (DIS '10). ACM, New York, NY, USA, 1-10. https://doi.org/10.1145/1858171.1858173

[19] Vasillis Vlachokyriakos, Clara Crivellaro, Pete Wright, Evika Karamagioli, EleniRevekka Staiou, Dimitris Gouscos, Rowan Thorpe, Antonio Krüger, Johannes Schöning, and Matt Jones. 2017. HCI, Solidarity Movements and the Solidarity Economy. In Proceedings of the 2017 CHI Conference on Human Factors in Computing Systems. ACM, 3126-3137.

[20] Ann Light, Alison Powell, and Irina Shklovski. 2017. Design for existential crisis in the anthropocene age. In Proceedings of the 8th International Conference on Communities and Technologies. ACM, 270-279.

[21] UTOPIA Project Group. 1981. The UTOPIA Project. On Training, Technology and Products Viewed from the Quality of Work Perspective. (1981).

[22] Philip Kraft and Jørgen P. Bansler. 1994. The collective resource approach: the Scandinavian experience. Scandinavian fournal of Information Systems 6, 1 (1994), 4.

[23] Joan Greenbaum. 1996. Post Modern Times: Participation Beyond the Workplace. In PDC. 65-72. http://ojs.ruc.dk/index.php/pdc/article/view/132

[24] Yvonne Dittrich, Sara Eriksén, and Christina Hansson. 2002. PD in the Wild; Evolving Practices of Design in Use. In Participatory Design Conference. http://swepub. kb.se/bib/swepub:oai:bth.se:forskinfoC8D549807517C422C1256BEA0050704B

[25] Carl DiSalvo, Andrew Clement, and Volkmar Pipek. 2012. Participatory design for, with, and by communities. In International Handbook of Participatory Design, Jesper Simonsen and Toni Robertson (Eds.). Routledge, Oxford, 182-209.

[26] Andrew Clement, Brenda McPhail, Karen Louise Smith, and Joseph Ferenbok. 2012. Probing, Mocking and Prototyping: Participatory Approaches to Identity Infrastructuring. In Proceedings of the 12th Participatory Design Conference: Research Papers - Volume 1 (PDC '12). ACM, New York, NY, USA, 21-30. https://doi.org/10.1145/2347635.2347639

[27] Christopher A. Le Dantec. 2016. Designing Publics. MIT Press.
[28] Maurizio Teli, Silvia Bordin, María Menéndez Blanco, Giusi Orabona, and Antonella De Angeli. 2015. Public design of digital commons in urban places: A case study. International fournal of Human-Computer Studies 81 (Sept. 2015), 17-30. https://doi.org/10.1016/j.ijhcs.2015.02.003

[29] Pål Castell. 2016. Institutional framing of citizen initiatives: a challenge for advancing public participation in Sweden. International Planning Studies 21, 4 (2016), 305-316. https://doi.org/10.1080/13563475.2015.1124756 arXiv:http://dx.doi.org/10.1080/13563475.2015.1124756

[30] Cristina Morini and Andrea Fumagalli. 2010. Life put to work: Towards a life theory of value. Ephemera: theory \& politics in organization 10, 3 (2010), 10-3. http://www.ephemerajournal.org/contribution/ life-put-work-towards-life-theory-value

[31] Morten Kyng. 2015. On creating and sustaining alternatives: the case of Danish telehealth. In Proceedings of The Fifth Decennial Aarhus Conference on Critical Alternatives. Aarhus University Press, 5-16.

[32] Sanna Marttila, Andrea Botero, and Joanna Saad-Sulonen. 2014. Towards commons design in participatory design. In Proceedings of the 13th Participatory Design Conference. ACM, 9-12. http://dl.acm.org/citation.cfm?id=2662187

[33] Nathan Schneider and Trebor Scholz (Eds.). 2017. Ours to Hack and to Own: The Rise of Platform Cooperativism, a New Vision for the Future of Work and a Fairer Internet. OR BOOKS.

[34] David Harvey. 2007. A Brief History of Neoliberalism. OUP Oxford.

[35] Thomas Piketty. 2014. Capital in the Twenty-First Century. Harvard University Press.

[36] Saskia Sassen. 2001. The Global City: New York, London, Tokyo. (2 edition ed.). Princeton University Press, Princeton, N.J.

[37] Gillian Tett. 2009. Fool's gold: how the bold dream of a small tribe at 7.P. Morgan was corrupted by Wall Street greed and unleashed a catastrophe. Simon and Schuster.

[38] Hamid R. Ekbia and Bonnie A. Nardi. 2017. Heteromation, and Other Stories of Computing and Capitalism. MIT Press.

[39] Christian Fuchs. 2012. Dallas Smythe Today-The Audience Commodity, the Digital Labour Debate, Marxist Political Economy and Critical Theory. Prolegomena to a Digital Labour Theory of Value. tripleC: Communication, Capitalism \& Critique. Open Access fournal for a Global Sustainable Information Society 10, 2 (2012), 692-740. http://www.triplec.at/index.php/tripleC/article/view/443

[40] José van Dijck. 2013. The Culture of Connectivity: A Critical History of Social Media. Oxford University Press.

[41] Andrea Fumagalli and Stefano Lucarelli. 2015. Finance, Austerity and Commonfare. Theory, Culture \& Society 32, 7-8 (Dec. 2015), 51-65. https://doi.org/10. 1177/0263276415597771

[42] General Intellect. 2018. Commonfare or the Welfare of the Commonwealth. In MoneyLabReader \#2: Overcoming the Hype. Institute of Net Cultures, Amsterdam, 243-251. http://networkcultures.org/blog/publication/ moneylab-reader-2-overcoming-the-hype/

[43] Eurostat. 2017. People at risk of poverty or social exclusion - Statistics Explained. (2017). http://ec.europa.eu/eurostat/statistics-explained/index.php/People_at_ risk_of_poverty_or_social_exclusion

[44] Fabrizio Sestini. 2012. Collective awareness platforms: Engines for sustainability and ethics. Technology and Society Magazine, IEEE 31, 4 (2012), 54-62. http: //ieeexplore.ieee.org/xpls/abs_all.jsp?arnumber=6387972

[45] Francesco Botto and Maurizio Teli. 2017. PIE News. A public design project toward commonfare. The Journal of Community Informatics 13, 2 (Aug. 2017). http://www.ci-journal.net/index.php/ciej/article/view/1383

[46] Peter Lyle, Mariacristina Sciannamblo, and Maurizio Teli. 2018. Fostering Commonfare. Infrastructuring Autonomous Social Collaboration. In Proceedings of the 2018 CHI Conference on Human Factors in Computing Systems (CHI '18). ACM, New York, NY, USA, Article 452, 12 pages. https://doi.org/10.1145/3173574.3174026

[47] Giuseppe Allegri, Sandra Bencic, Vladimir Cvijanovic, Andrea Fumagalli, Sandro Gobetti, Cristina Morini, Daniela Paes Leão, Maja Pleic, Luca Santini, Rachele Serino, and Merel Willemsen. 2017. PIE News - Research Report. Research Report D2.1 produced for the PIE News project (3 2017). http://pieproject.eu/wp-content/ uploads/2017/03/PIE D2.1.pdf

[48] Anna Wilson, Marco Sachy, Stefania Ottaviano, Francesco De Pellegrini, and Stefano De Paoli. 2017. PIE News - User Research Report and Scenarios. Research Report D3.1 produced for the PIE News project (6 2017). http://pieproject.eu/ wp-content/uploads/2017/07/PIE_D3.1_FIN.pdf

[49] Peter Lyle, Mariacristina Sciannamblo, and Maurizio Teli. 2017. Fostering Commonfare. Strategies and Tactics in a Collaborative Project. In Proceedings of the 29th Australian Conference on Computer-Human Interaction (OZCHI '17). ACM, New York, NY, USA, 443-447. https://doi.org/10.1145/3152771.3156154 